\title{
An evaluation of emergency pain management practices in fragility fractures of the pelvis
}

\author{
Uyen Evelyn Tran ${ }^{1} \cdot$ Krishan Yadav $^{1,3} \cdot{\text { Mohamed Mohamed } \text { Ali }^{2} \cdot \text { Michael Austin }}^{1,3,5} \cdot$ Marie-Joe Nemnom $^{3}$. \\ Debra Eagles ${ }^{1,3,4}$
}

Received: 17 May 2021 / Accepted: 11 January 2022 / Published online: 7 February 2022

(c) The Author(s), under exclusive licence to Canadian Association of Emergency Physicians (CAEP)/ Association Canadienne de Médecine d'Urgence (ACMU) 2022

\begin{abstract}
Background Inadequately treated pain is associated with significant morbidity in older adults. We aimed to describe current pain management practices for patients with fragility pelvic fractures, a common emergency department (ED) presentation in older adults.

Methods We performed a health records' review of adults $\geq 65$ years old who presented to two academic EDs with nonoperative fragility pelvic fractures between 01/2014 and 09/2018. The primary outcome measures were type and timing of analgesic medications. Secondary outcome measures included ancillary service consultation, ED length of stay, admission rate and rate of return to ED at 30 days. Data were reported using descriptive statistics.

Results We included 411 patients. The majority were female $(339,82.5 \%)$ with mean age 83.9 (SD 8.1) years. Nearly, onethird (130, 31.6\%) did not receive any analgesia for their fracture. Analgesia was initiated in 123 (29.9\%) patients through paramedic and nursing medical directives; 244 (59.4\%) patients received physician-initiated opioids (hydromorphone 228 (55.5\%); morphine $28(6.8 \%)$ ). Only $23.1 \%$ of patients received one or more ancillary services: physiotherapy (10.5\%), social work (7.3\%), geriatric nurse assessment (14.1\%), and homecare (3.9\%). Mean ED length of stay was 11.6 (SD 7.1) h; 210 (51.1\%) patients were admitted; of those discharged, 45 (22.4\%) returned to the ED within 30 days.

Conclusion One in three older adults presenting to the ED with nonoperative fragility pelvic fractures receive no analgesia during the course of their prehospital and ED care. Barriers to quality care must be identified and processes implemented to ensure adequate pain management for this population.
\end{abstract}

Keywords Fragility pelvic fracture $\cdot$ Pain $\cdot$ Older $\cdot$ Emergency Department

\section{Résumé}

Contexte La douleur insuffisamment traitée est associée à une morbidité importante chez les personnes âgées. Nous voulions décrire les pratiques actuelles de gestion de la douleur chez les patients souffrant de fractures pelviennes de fragilité, une présentation courante des services d'urgence (SU) chez les personnes âgées.

Méthodes Nous avons effectué une revue des dossiers médicaux des adultes $\geq 65$ ans qui se sont présentés à deux urgences universitaires avec des fractures pelviennes de fragilité non opérées entre 01/2014 et 09/2018. Les principaux critères d'évaluation étaient le type et le moment de la prise de médicaments analgésiques. Les critères d'évaluation secondaires

The results of this study have been accepted for presentation at the Canadian Association of Emergency Physicians Annual Scientific Conference, Winnipeg, Canada, June 2021.

Debra Eagles

deagles@toh.ca

1 Department of Emergency Medicine, University of Ottawa, Ottawa, ON, Canada

2 Western University, London, ON, Canada
3 Clinical Epidemiology Program, Ottawa Hospital Research Institute, F658a, Civic Campus, 1053 Carling Ave, Ottawa, ON K1Y 4E9, Canada

4 School of Epidemiology and Public Health, University of Ottawa, Ottawa, ON, Canada

5 Regional Paramedic Program for Eastern Ontario, Ottawa, ON, Canada 
comprennent la consultation des services auxiliaires, la durée moyenne de séjour aux urgences, le taux d'admission et le taux de retour aux urgences à 30 jours. Les données ont été rapportées en utilisant des statistiques descriptives.

Résultats Nous avons inclus 411 patients. La majorité était des femmes $(339,82,5 \%)$ avec un âge moyen de 83,9 (écarttype 8,1$)$ ans. Près d'un tiers $(130,31,6 \%)$ n'ont reçu aucune analgésie pour leur fracture. L'analgésie a été initiée chez 123 $(29,9 \%)$ patients par des directives médicales paramédicales et infirmières ; $244(59,4 \%)$ patients ont reçu des opioïdes à l'initiative du médecin (hydromorphone 228 (55,5\%) ; morphine $28(6,8 \%)$ ). Seuls 23,1\% des patients ont bénéficié d'un ou plusieurs services auxiliaires : physiothérapie (10,5\%), travail social (7,3\%), évaluation infirmière gériatrique (14,1\%) et soins à domicile $(3,9 \%)$. La durée moyenne de séjour aux urgences était de 11,6 heures (écart-type : 7,1); $210(51,1 \%)$ patients ont été admis ; parmi ceux qui sont sortis, $45(22,4 \%)$ sont retournés aux urgences dans les 30 jours.

Conclusion Une personne âgée sur trois se présentant aux urgences avec des fractures du bassin non opératoires ne reçoit aucune analgésie au cours de ses soins préhospitaliers et aux urgences. Les obstacles à la qualité des soins doivent être identifiés et des processus doivent être mis en œuvre pour assurer une gestion adéquate de la douleur pour cette population.

\section{Clinicians' capsule}

What is known about the topic?

Oligoanaesthesia is a common problem in older adults presenting to the emergency department (ED) with pain.

\section{What did this study ask?}

What are the current pain management practices for older adults with fragility pelvic fractures presenting to the ED?

\section{What did this study find?}

Nearly $1 / 3$ of older adults presenting to the ED with pelvic fragility fractures received no analgesia.

\section{Why does this study matter to clinicians?}

Emergency physicians need to do better to manage painful conditions in older EDpatients.

\section{Introduction}

Undertreatment of pain, or oligoanalgesia, is a recognized problem in emergency medicine, and it is particularly prevalent in older patients $[1,2]$. When presenting with injuries, they wait longer to receive analgesia and are less likely than younger patients to receive pain medication in the emergency department (ED). Inadequately treated pain in older people can lead to longer hospital length of stay, persistent pain, delirium, decreased mobility and subsequent functional decline [2].

A previous study reported the incidence of fragility pelvic fractures has tripled over the past few decades. The incidence was noted to be 92 per 100,000 patients [3]. The 1-year mortality rate of low energy pelvic fractures can be as high as $23 \%$ [4]. Patients are at significant risk of developing chronic pain and subsequently losing the ability to regain their prior level of functioning [2]. Thus, appropriate pain management and careful discharge planning by the ED physician are crucial for ensuring good patient outcomes.

The primary objective of this study was to describe current pain management practices for ED patients with pelvic fragility fractures in the different phases of care (paramedicinitiated in the prehospital setting, nursing-initiated prior to physician assessment, and physician-initiated). Secondary outcomes were admission rate, consultation to allied health care services, ED length of stay, and rate of return ED visits.

\section{Methods}

\section{Study design and setting}

We performed a health records review of older adults with fragility pelvic fractures who presented to two tertiary care EDs, with a combined annual census of 180,000 visits, between January 2014 and September 2018. Older adults represent one-quarter of ED visits. One of the sites is a trauma centre. The study was approved by the Ottawa Health Science Network Research Ethics Board.

\section{Population}

We included a consecutive sample of ED patients who were $\geq 65$ years of age and had sustained a fragility pelvic fracture that was managed conservatively. We defined fragility pelvic fractures as undisplaced or minimally displaced fractures of both anterior and posterior components of the pelvis that were identified on either X-ray or computerized tomography scans [5]. Exclusion criteria included: (1) admitted to hospital for reasons unrelated to their pelvic fracture; (2) multisystem trauma; (3) operative management; (4) privacy restriction on chart; or (5) transfer from another centre. 


\section{Study protocol and data abstraction}

A list of eligible cases was provided by The Ottawa Hospital data warehouse by searching relevant dates for discharge diagnoses with the following International Classification of Diseases, 10th version, Canada (ICD-10-CA) codes: S32100 (fracture of sacrum, closed), S32500 (fracture of pubis, closed), S32501 (fracture of pubis, open), S32800 (fracture of other and unspecified parts of lumbar spine and pelvis, closed), and S32801(fracture of other and unspecified parts of lumbar spine and pelvis, open). We included codes S32501 and S32801 to ensure that no cases of fragility pelvic fractures were missed in our search. Any open fracture was excluded. Data were extracted and input into a standardized case record form by two abstractors. All variables and primary outcomes of interest were explicitly defined within the form to ensure robust and consistent data collection. The data abstractors had regular meetings to ensure that any discrepancies were addressed by consensus. We determined the proportion of agreement for inclusion of cases by examining a random $10 \%$ sample of the total cohort ( $N=43$ cases). The proportion of agreement was 95.4\% (95\% CI 82.9-99.2) Demographic variables collected include age, sex, place of residence, home medications and number of comorbidities (as listed in their past medical history). Other data collected consisted of type and dose of analgesia received, ancillary services offered, need for return to ED within 30 days and ED length of stay.

\section{Outcome measures}

The primary outcome measures were type, quantity and timing of analgesic medications. Timing was divided by phases of care: prehospital-initiated (in those arriving by ambulance), nursing-initiated and physician-initiated. Nursing-initiated medications included those that could be administered based on a medical directive (non-steroidal anti-inflammatory drugs and acetaminophen) and analgesic medications (opioids) that could be administered with physician oversight. Physician-initiated medications were those that were ordered after the patient was evaluated by the ED physician. Secondary outcome measures included: admission rate, consultation to allied health services (geriatric nurse, physiotherapy, social work), ED length of stay (defined as time from arrival to time marked as discharged or dispositioned by the ED physician) and rate of return to ED within 1 month of discharge.

\section{Statistical analysis}

Presented analysis included: frequencies with percentages for categorical variables and means with standard deviations (SD) or medians with interquartile ranges (IQR) for continuous variables. To determine if differences between groups were significant, Chi-square tests and Mann-Whitney $U$ tests were used when comparing proportions, means and medians, respectively. In our hypothesis, we were testing if the proportions (Chi-square) or the variable distributions (Mann-Whitney) were equal between the two groups. The comparisons were planned a priori. Statistical analyses were completed using SAS version 9.4 (SAS Institute, Inc., Cary, NC).

\section{Results}

We included 411/604 older patients with fragility pelvic fractures (Appendix 1). The mean age was 83.9 (SD 8.1) years. The majority were female $(339,82.5 \%)$, arrived by ambulance $(337,82.0 \%)$ and were from their own home $(244,59.4 \%)$. Approximately, half $(210,51.1 \%)$ were admitted to hospital (Table 1). Data shows $42(20.0 \%)$ admitted patients and 45 (22.4\%) discharged patients were on home analgesia. The median number of comorbidities that patients in the admitted and discharged group were 5 (IQR 3-7) and 4 (IQR 3-6), respectively.

Table 1 shows the analgesia administered to older patients with pelvic fragility fractures throughout the phases of care. Nearly, one-third of patients $(130,31.6 \%)$ received no analgesia for their fracture and of these, $46(35.4 \%)$ subsequently were admitted to hospital. Only one in six patients (69, $16.8 \%$ ) received pain medication through nursing medical directives and similarly, approximately one in six patients $(54,16.0 \%)$ were administered analgesia through paramedicinitiated protocols. There were 244 (59.4\%) patients who received physician-initiated opioids for their pain. Patients were more often given hydromorphone $(228,55.5 \%)$ than morphine $(28,6.8 \%)$. Overall, admitted patients were more likely to be treated with opioids ( 71.0 vs $47.3 \%, p<0.001$ ) than patients who were discharged but there was no significant difference in the median dose received between the two groups. Mean length of stay for all patients was 11.6 (SD 7.1) hours. While in the ED, only 95 (23.1\%) patients were offered at least one allied health consultation: physiotherapy $(43,10.5 \%)$, social work $(30,7.3 \%)$, geriatric nurse assessment $(58,14.1 \%)$, and homecare $(16,3.9 \%)$. Of these, 19 (9.1\%) patients were in the admitted group and 76 (37.8\%) were in the discharged group. Within 1 month of discharge from the ED, 45 (22.4\%) patients returned, of whom 17 $(37.8 \%)$ required hospital admission on their second visit.

\section{Discussion}

This health records review describes the pain management of older adults presenting to the ED with nonoperative fragility pelvic fractures. Despite a prolonged ED course, approximately one-third of patients received no analgesia during their prehospital or ED phase of care. Few were 
Table 1 Baseline characteristics and pain management interventions for Emergency Department patients $\geq 65$ years of age with fragility fractures of the pelvis $(N=411)$

\begin{tabular}{|c|c|c|c|}
\hline & $\begin{array}{l}\text { All patients } \\
N=411\end{array}$ & $\begin{array}{l}\text { Admitted } \\
N=210\end{array}$ & $\begin{array}{l}\text { Discharged } \\
N=201\end{array}$ \\
\hline \multicolumn{4}{|l|}{ Age (years) } \\
\hline $\begin{array}{l}\text { Mean (SD) } \\
\text { Range }\end{array}$ & $\begin{array}{l}83.9(8.1) \\
65-105\end{array}$ & $\begin{array}{l}84.5(8.2) \\
66-105\end{array}$ & $\begin{array}{l}83.2(8.0) \\
65-101\end{array}$ \\
\hline Female, $n(\%)$ & $339(82.5)$ & $171(81.4)$ & $168(83.6)$ \\
\hline Arrival by ambulance, $n(\%)$ & $337(82.0)$ & $189(90.0)$ & $148(73.6)$ \\
\hline \multicolumn{4}{|l|}{ Residence $^{*}, n(\%)$} \\
\hline $\begin{array}{l}\text { Home } \\
\text { Retirement home } \\
\text { Long-term care }\end{array}$ & $\begin{array}{l}244(59.4) \\
88(21.4) \\
74(18.0)\end{array}$ & $\begin{array}{l}132(62.9) \\
47(22.4) \\
28(13.3)\end{array}$ & $\begin{array}{l}112(55.7) \\
41(20.4) \\
46(22.9)\end{array}$ \\
\hline \multicolumn{4}{|l|}{ Home medications, $n(\%)$} \\
\hline $\begin{array}{l}\text { Hydromorphone } \\
\text { Gabapentin } \\
\text { Pregabalin } \\
\text { Tramadol } \\
\text { Morphine } \\
\text { Fentanyl patch } \\
\text { Oxycodone }\end{array}$ & $\begin{array}{l}32(7.8) \\
15(3.7) \\
15(3.7) \\
14(3.4) \\
6(1.5) \\
4(1.0) \\
1(0.2)\end{array}$ & $\begin{array}{l}18(8.6) \\
8(3.8) \\
7(3.3) \\
3(1.4) \\
3(1.4) \\
3(1.4) \\
0(0.0)\end{array}$ & $\begin{array}{l}14(7.0) \\
7(3.5) \\
8(4.0) \\
11(5.5) \\
3(1.5) \\
1(0.5) \\
1(0.5)\end{array}$ \\
\hline Number of comorbidities, median (IQR) & $4(3-6)$ & $5(3-7)$ & $4(3-6)$ \\
\hline Analgesia initiated, $n(\%)$ & $\begin{array}{l}281(68.4) \\
n=337\end{array}$ & $\begin{array}{l}164(78.1) \\
n=189\end{array}$ & $\begin{array}{l}117(58.2) \\
n=148\end{array}$ \\
\hline $\begin{array}{l}\text { Paramedic-initiated analgesia, } n(\%) \\
\text { Acetaminophen } \\
\text { NSAIDs } \\
\text { Morphine } \\
\text { Fentanyl }\end{array}$ & $\begin{array}{l}54(16.0) \\
19(5.6) \\
12(3.6) \\
27(8.0) \\
5(1.5)\end{array}$ & $\begin{array}{l}33(17.5) \\
8(4.2) \\
5(2.7) \\
18(9.5) \\
5(2.7)\end{array}$ & $\begin{array}{l}21(14.2) \\
11(7.4) \\
7(4.7) \\
9(6.1) \\
0(0.0)\end{array}$ \\
\hline $\begin{array}{l}\text { Nursing-initiated analgesia, } n(\%) \\
\text { Acetaminophen } \\
\text { NSAIDs } \\
\text { Tramadol } \\
\text { Morphine } \\
\text { Dose (mg), median (IQR) } \\
\text { Hydromorphone } \\
\text { Dose (mg), median (IQR) }\end{array}$ & $\begin{array}{l}69(16.8) \\
48(11.7) \\
22(5.4) \\
34(8.3) \\
3(0.7) \\
4(1-5) \\
16(3.9) \\
1.0(0.5-1.0)\end{array}$ & $\begin{array}{l}37(17.6) \\
25(11.9) \\
12(5.7) \\
15(7.1) \\
2(1.0) \\
3(1-5) \\
10(4.8) \\
1.0(0.5-1.0)\end{array}$ & $\begin{array}{l}32(15.9) \\
23(11.4) \\
10(5.0) \\
19(9.5) \\
1(0.5) \\
4(4-4) \\
6(3.0) \\
0.8(0.5-1.0)\end{array}$ \\
\hline $\begin{array}{l}\text { Physician-initiated analgesia, } n(\%) \\
\text { Morphine } \\
\text { Dose (mg), median (IQR) } \\
\text { Hydromorphone } \\
\text { Dose (mg), median (IQR) }\end{array}$ & $\begin{array}{l}244(59.4) \\
28(6.8) \\
5(4-7.5) \\
228(55.5) \\
1.0(0.5-2.0)\end{array}$ & $\begin{array}{l}149(71.0) \\
21(10.0) \\
5(4-7.5) \\
138(65.7) \\
1.0(0.5-2.0)\end{array}$ & $\begin{array}{l}95(47.3) \\
7(3.5) \\
5(5-10) \\
90(44.8) \\
1.0(0.5-2.0)\end{array}$ \\
\hline $\begin{array}{l}\text { Allied health services, } n(\%) \\
\text { Physiotherapy } \\
\text { Social work } \\
\text { GEM nurse assessment } \\
\text { Homecare services } \\
\text { None }\end{array}$ & $\begin{array}{l}95(23.1) \\
43(10.5) \\
30(7.3) \\
58(14.1) \\
16(3.9) \\
316(76.9)\end{array}$ & $\begin{array}{l}19(9.1) \\
9(4.3) \\
7(3.3) \\
9(4.3) \\
1(0.5) \\
191(91.0)\end{array}$ & $\begin{array}{l}76(37.8) \\
34(16.9) \\
23(11.4) \\
49(24.4) \\
15(7.5) \\
125(62.2)\end{array}$ \\
\hline \multicolumn{4}{|l|}{ ED length of stay (h) } \\
\hline Median (IQR) & $9.5(6.1-15.5)$ & $10.5(7.7-16.0)$ & $7.7(5.2-14.9)$ \\
\hline $\begin{array}{l}\text { Discharged and RTED, } n(\%) \\
\text { RTED and discharged } \\
\text { RTED and admitted }\end{array}$ & $\begin{array}{l}45(10.9) \\
28(6.8) \\
17(4.1)\end{array}$ & $\begin{array}{l}0(0.0) \\
0(0.0) \\
0(0.0)\end{array}$ & $\begin{array}{l}45(22.4) \\
28(13.9) \\
17(8.5)\end{array}$ \\
\hline
\end{tabular}

$S D$ standard deviation, IQR interquartile range, GEM Geriatric Emergency Management, NSAIDs non-steroidal anti-inflammatory agents (including ibuprofen, naproxen, or ketorolac), $E D$ Emergency Department, $R T E D$ return to Emergency Department

*All patients $N=406$, admitted $N=207$, discharged $N=199$ 
seen by allied health care professionals. Half of the patients required admission to hospital and of those discharged, one in five returned to the ED within 30 days.

Our finding that a significant proportion of patients receive no analgesia within the ED is consistent with Brown et al.'s ED study examining analgesia management of isolated closed extremity and clavicular fractures. They found $42 \%$ of patients over the age of 70 were not provided any analgesia, even when patients reported moderate to high levels of pain [6]. A study evaluating the impact of age on pain perception in the ED, found that older adults experience the same level of pain as their younger counterparts from dislocations and fractures [7]. Yet, it has been widely described in the literature that older adults are less likely to receive analgesia. In a study by Daoust et al., older patients with moderate to severe pain waited $1.1 \mathrm{~h}(55.2 \%)$ longer than younger patients before being administered pain medication [1].

Recent guidelines for pain management in acute musculoskeletal pain do not contain specific recommendations for the care of older people who sustain these injuries [8]. Similarly, guidelines including those recently published by the British Pain Society for the management of pain in older patients do not address the management of acute pain [9]. While specific recommendations within guidelines are lacking, specific quality indicators related to the assessment and management of acute pain in older adults have been proposed [10].

We are unable to assess the patients' pain severity and the impact that this may have had on analgesia provided, which is a limitation we recognize as part of a health record review. Important data such as pain scores were lacking in the available charts. Accordingly, we are unable to comment on oligoanaesthesia directly. However, it is unlikely that all patients who did not receive analgesia had a no/low level of pain as $25 \%$ of those admitted had not received analgesia. This study was undertaken at two tertiary care EDs; it is difficult to know if our findings are generalizable to other centres. Furthermore, dosing of analgesia prior to paramedic/ED presentation would have influenced downstream decisions but was not accounted for in our study.

\section{Conclusion}

Nearly, one-third of older adults presenting to the ED with pelvic fragility fractures received no analgesia. Advanced medical directives for analgesia and ancillary health services were underutilized. It is imperative that barriers to quality care are identified and processes implemented to improve pain management for this population.

Supplementary Information The online version contains supplementary material available at https://doi.org/10.1007/s43678-022-00265-5.

Acknowledgements We thank Ms. Angela Marcantonio for her assistance with this project.

Author contributions ET was responsible for study development, data collection, monitoring of data abstraction, and writing of the manuscript. MMA assisted with data abstraction and contributed to the methods section of the manuscript. MJN provided valuable input on data analysis and contributed to the analysis section of the manuscript. DE, MA and KY were involved with study design and development. All the authors provided substantive feedback on the manuscript.

Funding There are no funding sources.

\section{Declarations}

Conflict of interest The authors have no conflicts of interest to declare

\section{References}

1. Daoust R, Paquet J, Lavigne G, Sanogo K, Chauny JM. Senior patients with moderate to severe pain wait longer for analgesic medication in EDs. Am J Emerg Med. 2014;32(4):315-9.

2. Hwang U, Platts-Mills TF. Acute pain management in older adults in the emergency department. Clin Geriatr Med. 2013;29(1):151-64.

3. Kannus P, Palvanen M, Niemi S, Parkkari J, Jarvinen M. Epidemiology of osteoporotic pelvic fractures in elderly people in Finland: sharp increase in 1970-1997 and alarming projections for the new millennium. Osteoporos Int. 2000;11(5):443-8.

4. Mears SC, Berry DJ. Outcomes of displaced and nondisplaced pelvic and sacral fractures in elderly adults. J Am Geriatr Soc. 2011;59(7):1309-12.

5. Rommens PM, Arand C, Hofmann A, Wagner D. When and how to operate fragility fractures of the pelvis? Indian J Orthop. 2019;53(1):128-37.

6. Brown JC, Klein EJ, Lewis CW, Johnston BD, Cummings P. Emergency department analgesia for fracture pain. Ann Emerg Med. 2003;42(2):197-205.

7. Daoust R, Paquet J, Piette E, Sanogo K, Bailey B, Chauny JM. Impact of age on pain perception for typical painful diagnoses in the emergency department. J Emerg Med. 2016;50(1):14-20.

8. Hsu JR, Mir H, Wally MK, Seymour RB, Orthopaedic Trauma Association Musculoskeletal Pain Task F. Clinical practice guidelines for pain management in acute musculoskeletal injury. J Orthop Trauma. 2019;33(5):158-82.

9. Dunham M, Schofield P, Knaggs R. Evidence-based clinical practice guidelines on the management of pain in older people - a summary report. Br J Pain. 2013;7(3):152-4.

10. Terrell KM, Hustey FM, Hwang U, Gerson LW, Wenger NS, Miller DK. Quality indicators for geriatric emergency care. Acad Emerg Med. 2009;16(5):441-9. 